\title{
Management of pseudohypoparathyroidism in pregnancy: a rare entity
}

\author{
Mrinalini Sinha*, Anjum Ara, Indu C. Chug, Saunri Hansadah, Avani Goyal
}

Department of Obstetrics and Gynecology, Dr. Ram Manohar Lohia Hospital, New Delhi, India

Received: 02 July 2019

Accepted: 14 August 2019

\section{*Correspondence:}

Dr. Mrinalini Sinha,

E-mail: mrinalini.lyf@gmail.com

Copyright: ( ) the author(s), publisher and licensee Medip Academy. This is an open-access article distributed under the terms of the Creative Commons Attribution Non-Commercial License, which permits unrestricted non-commercial use, distribution, and reproduction in any medium, provided the original work is properly cited.

\begin{abstract}
Pseudohypoparathyroidism is a very rare genetic disorder and during pregnancy poses multiple challenges related to its monitoring and management. Authors present the case of a 30year old primigravida who was a diagnosed case of pseudohypoparathyroidism since 22 yrs of age, presented to our obs/gynae OPD at $5+5$ wks of POG. She was managed by serial monitoring of serum calcium, phosphate and vitamin D throughout pregnancy with careful dose modification of calcium from $1 \mathrm{gm}$ to $3.5 \mathrm{gm}$ daily and vitamin D from $0.5 \mathrm{mcg}$ to $1.5 \mathrm{mcg}$ daily. During her course of pregnancy, she developed gestational hypothyroidism, gestational diabetes mellitus, intrahepatic cholestasis of pregnancy and gestational hypertension which were controlled and managed successfully. She had an elective caesarean section at 37+6 wks POG for transverse lie. Both maternal and perinatal outcome were good. Patient was discharged with advice to continue with her monitoring of serum calcium, phosphate, vitamin $\mathrm{D}$ along with supplementation of calcium and vitamin D life long.
\end{abstract}

Keywords: Pseudohypoparathyroidism, Serum calcium, Vitamin D

\section{INTRODUCTION}

Pseudohypoparathyroidism (PHP) is a very rare genetic disorder of calcium metabolism resulting from renal resistance to parathyroid hormone. It is represented by impaired signaling of PTH that activate cAMP-dependent pathways via Gs $\alpha$ protein. ${ }^{1,2}$ Pregnancy also is commonly associated with altered calcium metabolism. As a result, these two conditions in combination poses multiple diagnostic and management related challenges. There are very few cases of pregnancy and pseudohypoparathyroidism reported in literature.

\section{CASE REPORT}

A 30 year old short statured primigravida was referred from endocrine OPD as a diagnosed case of pseudohypoparathyroidism type 1 a with $5+5$ weeks POG. She has been married for 2 years and present pregnancy was a spontaneous conception. She had attained menarche at 13 years of age with regular cycles and average flow. There is history of focal seizures with carpopedal spasm at 11 years of age when she was started on anticonvulsants. Her treatment continued till about 8 years back when she again developed focal seizures associated with fall. With thorough investigations (low S.Ca : $5.1 \mathrm{mg} / \mathrm{dl}$, high PTH : $127.9 \mathrm{pg} / \mathrm{ml}$; EEG : Normal ; CT Brain : bilateral basal ganglia calcification ; USG : small calcific deposits in bilateral kidneys) she was diagnosed as PHP and was started on calcium supplementation (1gm/day) and vitamin $\mathrm{D}$ along with anticonvulsants. She also had h/o seizure disorder in her brother.

In her antenatal care, she was given folic acid, calcium (2gm/day) and vitamin $\mathrm{D}$ supplementation $(1,25$ dihydroxycholecalciferol $0.5 \mu \mathrm{g} /$ day) and anticonvulsants (Oxcarbazepine 600mg/day). Routine antenatal screening 
investigations were normal except for low $\mathrm{Hb}(8.2 \mathrm{gm} / \mathrm{dl})$ and high TSH $(6.6 \mathrm{mIU} / \mathrm{L})$, hence she was started on Levothyroxine $25 \mathrm{mcg} /$ day. Genetic counseling was also done.

At 23 weeks, when she developed leg cramps, serum calcium level was found to be low $(7 \mathrm{mg} / \mathrm{dl})$ despite calcium supplementation, therefore the dose of calcium was further increased to $3 \mathrm{gm} /$ day and Vitamin $\mathrm{D}$ to $1 \mu \mathrm{g} /$ day. Serial monitoring of serum calcium (fortnightly), phosphate, PTH, vitamin D was continued. Level 2 scan (Anomaly Scan) and Fetal Echo at 24 weeks revealed normal study while TSH was raised (4.5 $\mathrm{mIU} / \mathrm{L}$ ), requiring dose increment of Levothyroxine to $50 \mathrm{mcg} /$ day. Series of medical conditions were diagnosed at 26 weeks POG. Inspite of continued intake of oral hematinics, patient's $\mathrm{Hb}$ dropped to $7 \mathrm{gm} / \mathrm{dl}$ with iron profile studies s/o iron deficiency anemia - I/V Iron Sucrose infusion was given. With high GCT $(231 \mathrm{mg} / \mathrm{dl})$, diagnosis of GDM was made. Good glycemic control was achieved with medical nutritional therapy, physical exercise and long acting insulin. Patient was started and continued on ursodeoxycholic acid as she was also diagnosed as IHCP with severe itching over palms, soles and abdomen, deranged LFTs (SGOT - 292/ SGPT $325)$, high serum bile acid $(21.5 \mathrm{mg} / \mathrm{dl})$ and negative viral markers. Female was continued on regular antenatal checkups with good glycemic control, improved $\mathrm{Hb}$, normal TSH, decreasing liver enzymes, normal growth parameters on USG untill 35 weeks when she was admitted with high BP records $(160 / 100 \mathrm{mmHg})$ and no e/o albuminuria or any other signs and symptoms of impending eclampsia. She was diagnosed as Gestational HTN and was started on oral Labetalol (200mg/day).

Her general physical examination revealed round face, short stature (height - $143 \mathrm{~cm}$ ), short metacarpals, archibald sign, positive trousseau sign, obesity - BMI $29.3 \mathrm{~kg} / \mathrm{m}^{2}$ (pre pregnancy weight - $60 \mathrm{kgs}$ ) and abdominal examination revealed uniformly distended relaxed abdomen with uterine height corresponding to 34 weeks, transverse lie, regular FHR - 142 bpm. During her course of hospital stay, BP was well controlled, lab reports were serially monitored with no clinical or sonological e/o IUGR and normal color doppler studies. Pelvic assessment at 37 weeks revealed a contracted pelvis. She was managed in consultation with endocrinology, neurology, anaesthesia and was taken for elective caesarean section at $37+6$ weeks $P O G$ i/v/o transverse lie with contracted pelvis with IHCP. She delivered a healthy baby with birth wt. $2.6 \mathrm{kgs}$ and Apgar score -8 in $1 \mathrm{~min} ; 9$ in $5 \mathrm{~min}$. Immediate post-delivery, calcium gluconate infusion $(\sim 1 \mathrm{~g} / 10 \mathrm{ml})$ was given to keep serum calcium level $>7 \mathrm{mg} / \mathrm{dl}$. On POD2, calcium was found to be low $(7.2 \mathrm{mg} / \mathrm{dl})$, hence the dose was increased to $3.5 \mathrm{gm} /$ day and VitaminD to $1.5 \mu \mathrm{g} /$ day. Lactation was encouraged. Patient was discharged on POD7 with both mother and baby in stable condition. She was continued on oral hematinics, Calcium and Vitamin D supplementation. There was no e/o hypocalcemia in baby in post natal period. Female and her baby are asymptomatic in their follow up till 3 months post delivery.

\section{DISCUSSION}

Pseudohypoparathyroidism (PHP) : Rare genetic disorder of calcium metabolism resulting from renal resistance to parathyroid hormone (PTH), characterised by low serum calcium, high serum phosphate and normal/high $\mathrm{PTH} .{ }^{3}$ It is linked to dysfunctional $\mathrm{G}$ proteins (Gsa subunit). Overall prevalence- 7.2/1,000,000 or approx 1/1,40,000.

\section{Types of PHP}

1a : Albright's hereditary osteodystrophy: Most common type $-70 \%$, Autosomal Dominant, round facies, skeletal anomalies (short metacarpals - Figure 1), Archibald sign (absent knuckles - Figure 2), short stature, heterotopic calcifications, central obesity, developmental delay a/w TSH resistance. ${ }^{1,2}$

1b: Lacks the physical appearance of type 1a but is biochemically similar (PTH resistance).

2: Biochemically similar to type 1 , distinguished by differing urinary excretion of cAMP in response to exogenous PTH.

\section{Pseudo PHP}

Skeletal defects are seen with normal biochemical parameters, paternal inheritance, and no hormone resistance. Hypocalcemia appears only during growth and other periods of increased demand of calcium. ${ }^{4}$

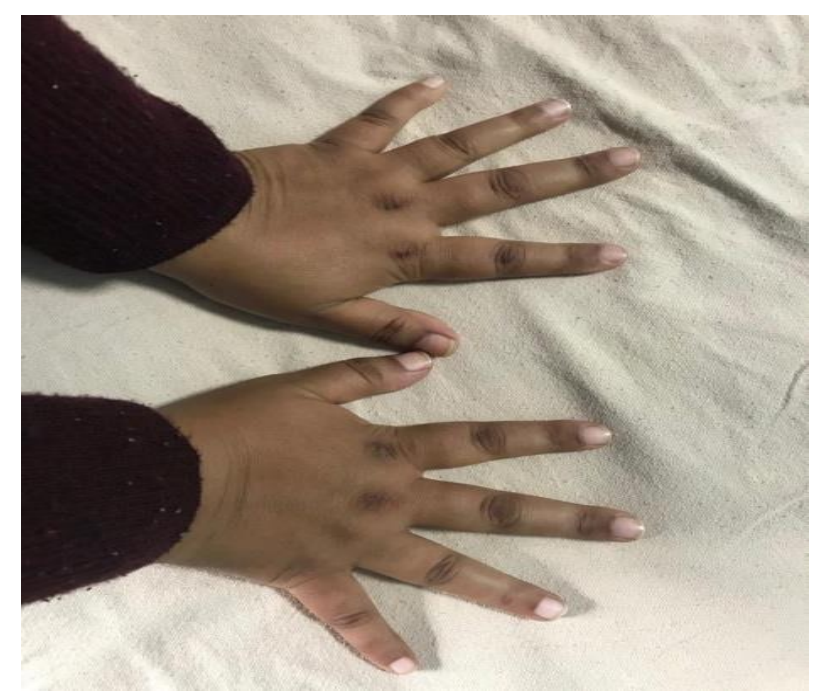

Figure 1: Short metacarpals.

Figure 1 and 2 shows the skeletal anomalies found in type 1a PHP (our patient had the above shown skeletal anomalies. 
Patients may present with symptoms of hypocalcemia, paresthesias, muscle cramps, tetany, carpopedal spasm, numbness, seizures. ${ }^{3,5}$ Most patients of type 1a PHP show TSH resistance. Frequent TFT monitoring with thyroxine supplementation (if required) is needed for euthyroid status. Our patient had TSH resistance.

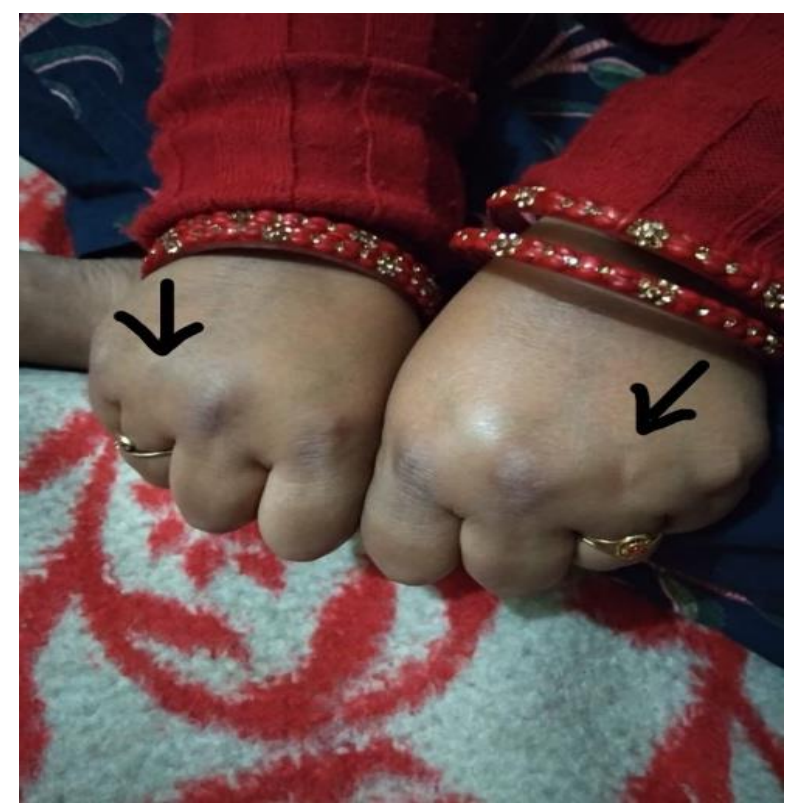

Figure 2: Archibald sign.

Female may have delayed puberty, oligomenorrhea, anovulation, infertility due to resistance to gonadotrophins. ${ }^{5}$ Our patient had normal menstrual cycle with spontaneous conception. There are increased risk of spontaneous abortion, pre term labor, still birth, IUGR, increased risk of tetany during labor due to hypocalcemia. ${ }^{3}$ Hyperventilation during labor may precipitate hypocalcemia and tetany, hence should be taken care of. Labor analgesia may be of help. ${ }^{6}$

There is abundant release of PTHrp from breast tissue during lactation that leads to increased $\mathrm{Ca}$ resorption from bones and kidneys, thereby causing hypercalcemia. Hence, frequent serum calcium monitoring has to be continued for dose adjustment of $\mathrm{Ca}$ supplementation. The goal of therapy is to maintain serum total and ionised calcium level within reference range while avoiding hypercalcemia, hypercalciuria and to suppress PTH to normal.

Hypercalcemia can suppress parathyroid gland of fetus causing hypocalcemia in the newborn. Transient secondary hyperparathyroidism may be seen in fetus, thereby causing skeletal demineralization, subperiosteal bone resorption and intrauterine fractures, effects usually resolves by 7-8 months of life.

\section{CONCLUSION}

Management of PHP in pregnancy needs regular serum calcium and vitamin D monitoring throughout pregnancy, labor and post partum period. Therapeutic supplementation of calcium and vitamin D is required in increased dosage. While supplementing with calcium and Vitamin D, care is to be taken to avoid overloading as it may lead to hypercalcemia, hypercalciuria and ectopic calcification. It is also essential to maintain Euthyroid level for normal fetal development, as most of the patients have TSH resistance. Regular monitoring and supplementation gives a good maternal and perinatal outcome.

Funding: No funding sources

Conflict of interest: None declared

Ethical approval: Not required

\section{REFERENCES}

1. Mantovani G. Pseudohypoparathyroidism diagnosis and treatment. J Clin Endocrinol Metabol. 2011;96(10):3020-30.

2. Ramallo PG. Management of pseudohypoparathyroidism in pregnancy: case report. J Obstet Gynaecol. 2016;37(4):519-20.

3. Singh A, Agarwal N. Management of pseudohypoparathyroidism type 1a during pregnancy and labor: case report. Hindawi Pub Corp Case Repo Obstet Gynecol. 2012;Article ID 629583:2.

4. Gershberg H, Weseley AC. Pseudohypoparathyroidism and pregnancy. The J Paediatr. 1960;56(3):383-6.

5. Ochiai D. Pseudohypoparathyroidism type $1 \mathrm{a}$ in pregnancy. J Obstet Gynaecol. 2013;33(8):900.

6. O'Donnell D, Costa J, Meyers AM. Management of pseudohypoparathyroidism in pregnancy: Case report. Br J Obstet Gynaecol. 1985;92(6):639-41.

Cite this article as: Sinha M, Ara A, Chug IC, Hansadah S, Goyal A. Management of pseudohypoparathyroidism in pregnancy: a rare entity. Int J Reprod Contracept Obstet Gynecol 2019;8:3798-800. 